\title{
A socialização do atendimento de energia elétrica no Rio de Janeiro
}

\section{RENATO TORRES M.C. VASCONCELOS}

Superintendente-geral de Desenvolvimento de Material e Serviços da LIGHT. Engenheiro eletricista pela Escola Nacional de Engenharia, administrador de empresas pela Universidade Gama Filho, foi superintendente de Eletrificacão de Interesse Social e superintendente-geral de Planejamento do Sistema e Comercial da LIGHT.

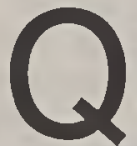
uando o controle acionário da LIGHT - Serviços de Eletricidade $S / A$., foi adquirido pelo Governo Federal, através da ELETROBRÁS, no final do ano de 1978 , verificaram os novos adminis tradores da empresa (a maioria engenheiros vindos da ELETROBRÁS) que existia, na área de concessão da empresa, quase dois milhões de habitantes (baseados nas informações da época; hoje, sabemos que este número é bem menor, oscilando em torno de, no máximo, 1.200.000) que não eram atendidos diretamente pela rede de distribuição de energia da concessionária. Eram os moradores das favelas dos loteamentos periféricos (a maioria loteamentos considerados "irregulares") e da zona rural da empresa.

Para se ter uma idéia, na época, a concessionária atendia a cerca de $\mathbf{1 . 5 0 0 . 0 0 0}$ consumidores residenciais (Sistema Rio), isto é, aproximadamente, $20 \%$ (utilizando-se as estimativas iniciais) ou $15 \%$ (utilizando-se as novas estimativas) dos moradores da área de concessão da empresa não eram atendidos, diretamente, pelos serviços públicos de energia elétrica.

O abastecimento de energia elétrica das favelas era efetuado através da intermediação de terceiros (comissões de luz, cabineiros, luz emprestada, etc.) e, para isto, pagavam os moradores tarifas mais elevadas (em alguns casos, chegava-se a valores de cerca de $50 \%$ ou, em casos extremos, de até $100 \%$ acima do que pagariam se fossem atendidos diretamente), arcavam com todos os custos dos investimentos (além do pagamento da conta de (uz), e eram atendidos precariamente (as redes, em sua grande maioria, se encontravam em péssimo estado de conservação e mal dimensionadas).

Os moradores das favelas, na sua quase totalidade, aglomerados de moradas resultantes de ocupações de terrenos baldios, pertencentes ao poder público (cerca de $33 \%$ ), a particulares (cerca de $27 \%$ ) e outros (cerca de $40 \%$ ), não eram atendidos oficial e globalmente por qualquer serviço público, como água, es. goto, limpeza urbana, etc. As redes de serviço público, porventura existentes, tinham sido construldas pelos moradores, com seus próprios recursos (apenas em alguns casos as redes elétricas, de água ou esgoto haviam sido construídas pelo estado ou este havia fornecido o material), cabendo, na quase totalidade dos casos, a administração e operação dos serviços aos próprios favelados, que se organizavam em associações de moradores, comissões de luz, de água, etc... Os favelados viviam, fruto de experiências passadas, com constantes receios da remoção.

Originários, em grande parte, da zona rural, de outros estados brasileiros, ou nascidos e criados dentro da própria favela, em sua grande maioria, não ti. nham "tradição" no atendimento pelo serviço público, gerando, com isto, um alto grau de desconfiança em relação à ação do estado, pois, esta, quase sempre, se fazia presente somente no sentido da remoção.

Em 1979, a LIGHT anunciou que iniciaria um programa, que visava estender suas redes de distribuição a todas as favelas e loteamentos "irregulares", exis. tentes em sua área de concessão, instalando, em cada moradia, o medidor individual de consumo. Com isto, a em. presa assumiria os investimentos, a operação e manutenção das redes, e os moradores das favelas receberiam as suas contas individualizadas, documento este que assumiria, também, o papel de um "atestado de residéncia". As conseqüências óbvias desta ação, seria uma conta de luz mais barata, um atendimento de melhor qualidade (energia fornecida dentro dos parâmetros de tensão e con. tinuidade fixada pela legislação do se. tor), além do atestado de residência que representava para a populaçāo favelada, senâo um verdadeiro título de propriedade, pelo menos a seguranca de que não seriam mais removidos e que os outros serviços públicos, também, poderiam ser estendidos àquela população.

Inicialmente, a empresa propôs às prefeituras de São Paulo e do Rio de Janeiro (naquela época a zona de concessão da LIGHT se estendia aos dois estados, mais tarde desmembrada pela compra do subsistema de São Paulo, pela ELETROPAULO) a assinatura de um protocolo de in tenções, no qual seriam acordadas as diretrizes básicas para ação nas favelas; procurou, também, a empresa estudar as novas áreas a serem eletrificadas, a fim de estudar e desenvolver padrões de construçōes de redes, além de procedimentos administrativos e comerciais adequados à realidade do novo mercado.

As moradias em favelas, em sua grande maioria, como já frisamos anteriormente, já eram servidas de energia elétrica, quer através de comissões de luz (as maiores), quer através de cabineiros, energia cedida por terceiros (vizinhos, moradores das ruas junto à rede da concessionária), ou mesmo através dos, já famosos, "Gatos" ou ligações irregulares.

Foram criados padrões de redes de distribuição alternativos, utilizando-se materiais existentes em estoque na concessionária, como postes de madeira (já utilizados na eletrificação rural), cabos multiplexados) para alta e baixa tensão, além de "filosofias" de projetos que procuravam evitar, ao máximo, a penetração de rede de alta tensão, e outras práticas no sentido de compatibilizar os fatores segurança, flexibilidade, confiabilidade e custo, com a realidade das favelas e dos loteamentos periféricos. Foi desenvolvido, também, um posto padrão de medição, pois foi verificado, no inlcio do programa, que se adotado às práticas utilizadas para o atendimento dos consumidores residenciais, isto é, de se aguardar que cada morador preparasse o seu PC de entrada, o programa se inviabilizaria, pois, nas primeiras favelas eletrificadas, adotando-se esta prática, o tempo de preparação do local de me- 
dição, pelos moradores, foi excessivamente longo.

Desta forma, foi adotado o posto com uma, duas ou três caixas de medição, instaladas pela própria concessionária e cobradas na conta de luz, como opção para o consumidor.

No Rio de Janeiro e, posteriormente, em São Paulo, foi criado o Departamento de Eletrificação de Interesse Social na estrutura da empresa, subordinada, naquela época, à Diretocia de Coordenação (basicamente uma diretoria de atendimento ao consumidor) que seria o responsável pela coordenação dos programas de eletrificação de favelas, loteamentos periféricos e rural.

8 asicamente, a necessidade de criacão deste Departamento, prendia-se ao fato de que irfamos desenvolver um programa que absorvia várias "zonas de concessão" e que, portanto, não irlamos lidar com consumidores individuais mas, sim, com a comunidade organizada, como foi dito acima, em associaçōes, em comissões, etc., com toda uma estrutu. ra de poder legal. Talvez, o modelo mais próximo, evidentemente com algumas diferenças óbvias, é o da absorção de qualquer nova área de concessão, em que se tem de desenvolver entendimentos com as prefeituras e câmaras municipais.

Inicialmente, a estratégia desenvolvida foi a de se manter entendimentos $\infty \mathrm{m}$ as organizaçōes locais, no sentido de, não só informarmos sobre o programa de eletrificação como, também, de colhermos subsidios junto à própria população que desenvolveria trabalhos de apoio, como cadastramento dos moradores, levantamenos, nos arquivos, de elementos para subsidiar a feitura dos projetos (como mapas, etc.), colocacão de nomes nas ruas e números nas casas, num trabalho integrado onde, na realidade, o que estava havendo era um fluxo"cont ínuo de experiéncias nos dois sentidos, que ajudavam, nảo só o técnico da empresa a conviver com a realidade das favelas e, com isto, mudar os seus conceitos pessoais, como técnicos, modificando a sua postura, frente ao problema de encontrar soluçōes para os projetos. Da parte da populaçāo favela. da, eram recebidas informaçōes quanto à prestação de um serviço público (com seus respectivos direitos e deveres) e, ao mesmo tempo, este contato servia para mudar a própria imagem do serviço público, para esta população.

Além dos entendimentos, individuais, dos técnicos da empresa, com favelados e suas lideranças, eram realizadas, também, assembléias locais, com a participação da população quando, utilizandose recursos audiovisuais, eram transmitidas as informaçōes e colhidas e dirimidas as dúvidas quanto ao processo de eletrificação.

Hoje, decorrido cinco anos do infcio do programa, que se deu em 29/11/79, já foram eletrificadas cerca de 465 favelas e, loteamentos nāo regularizados e atendidos, cerca de 156.000 domicŕlios, estimando-se em 800.000 habitantes beneficiados.

Os números básicos estão traduzidos nas tabelas abaixo, onde são fornecidas, também, informaçōes sobre os cortes e os consumos. Sobre estes itens, cabe informar que, quanto a inadimplência, esta era considerada uma das maiores barreiras ao programa de eletrificação, pois era transmitida a falsa impressāo que este grupo de consumidores, pelas suas condições sócioeconômica, iriam alcançar Indices que inviabilizaria o projeto. Os números, no entanto, desmentiram aquela premissa, pois o comportamento da curva de cortes se deu, exa- tamente, dentro das nossas previsões, isto é, uma curva tipo saturação, pois, inicialmente, a nossa expectativa, ante o significado do programa para a população favelada, faria com que estes indices se situassem dentro de limites inferiores e, posteriormente, devido a propria condição sócio-econômica da população favelada, este índice -cresceria até o limite superior compativel com sua condição sócio-econômica, registrando valores semelhantes a periferia da nossa área de concessão.

Assim, é que se observamos os valores, verificaremos que estes, no momento, evoluem, mas mantendo uma proporcionalidade com os demais consumidores residenciais de nossa área de concessāo.

Verificamos, também, que o consumo tem crescido, indicando, assim, não só uma melhoria na qualidade de vida, como, também, que não existe, pelo menos levando-se em conta uma abordagem macro, a chamada "tendência geral para as ligaçōes irregulares".

Independente das avaliaçōes internas da empresa, expressas nos números e

\section{QUADRO 1}

\section{LIGAÇÓES EM FAVELAS}

\begin{tabular}{l|c|c|c}
\hline \multicolumn{1}{|c|}{ ESPECIFICAÇĀ̄o } & $\begin{array}{c}\text { No de } \\
\text { Favelas }\end{array}$ & $\begin{array}{c}\text { No de } \\
\text { Ligaçöes }\end{array}$ & $\begin{array}{c}\text { No de } \\
\text { Habitantes }\end{array}$ \\
\hline Ligadas de Nov/79 a Setembro/84 & 465 & 155.309 & 776.454 \\
A ligar no Programa/84 & 97 & $25.314 *$ & 126.570 \\
Outros & $72^{*}$ & 6.747 & 33.735 \\
\hline
\end{tabular}

- Favelas cadastradas pelo IPLAN-Rio (Prefeitura) que năo foram ligadas e năo estão no programa de 1984.

*. Inclui pedidos de extensão de rede por comunidades ja ligadas.

\section{QUADRO 2}

\section{SITUAÇÃO DE CORTE E CONSUMO}

\begin{tabular}{|c|c|c|c|c|c|}
\hline \multirow{2}{*}{ ESPECIFICAÇĀO } & \multicolumn{2}{|c|}{ Consumo Mensal (kW) } & \multicolumn{3}{|c|}{ Ind. Mensal de Cortes (\%) } \\
\hline & Favela & Outros & Favela (1) & Outros (2) & $1 / 2$ \\
\hline 1981 (média) & 94.0 & 167.85 & 4,12 & 2,53 & 1,63 \\
\hline 1982 (media) & 102.0 & 167.21 & 4,52 & 3,21 & 1,44 \\
\hline 1983 (média & 115 & 183 & 6.23 & 2,89 & 2,15 \\
\hline JAN/84 & 119 & 202 & 7,38 & 3,39 & 2,17 \\
\hline FEV $/ 84$ & 118 & 211 & 9,06 & 4,46 & 2,03 \\
\hline MAR/84 & 118 & 212 & 9,41 & 4,24 & 2,21 \\
\hline $\mathrm{ABR} / 84$ & 96 & 171 & 9.48 & 4,61 & 2,05 \\
\hline $\mathrm{MAI} / 84$ & 102 & 178 & 9,89 & 4,58 & 2,18 \\
\hline JUN/84 & 99 & 173 & 9,00 & 4,67 & 1,92 \\
\hline JUL/84 & 91 & 167 & 8,86 & 4,12 & 2,15 \\
\hline AGO/84 & 92 & 177 & 7,65 & 3,46 & 2,21 \\
\hline SET $/ 84$ & 115 & 171 & 8,18 & 3,69 & 2,21 \\
\hline
\end{tabular}

- Consumidores residenciais normais 
comentários indicados, foi contratado recentemente os serviços da IBAM (Instituto Brasileiro de Administração Municipal), para que fizesse uma avaliação do impacto da implantação de um serviço público (o de energia elétrica) nas populaçōes faveladas).

A eletrificação dos loteamentos irregulares, tem seguido a mesma estratégia operacional do programa de eletrificação de favelas, com pequenas adaptações, compatibilizando-se com a realidade deste segmento da população.

Dentro do planejamento da empresa está previsto que, até 1987 , estes programas estarão concluídos, quando, então, serão alcançados os objetivos fixa. dos pela administração da empresa, de levar a todas as moradias, situadas nes. tes locais, o serviço público da energia elétrica.

No Programa de Eletrificação Rural, a situação encontrada era a de que os atendimentos efetuados pela empresa, ao longo do tempo, tinha sido sempre subordinado ao Decreto 41.019 , isto é, atendendo à solicitação do proprietário, a empresa elaborava o orcamento para atendé-lo, este era pago à vista, antecipadamente, e o consumidor era atendido.

Por ser uma empresa com características urbanas, os padrões de construção, utilizados para as redes rurais, eram adaptaçōes dos padrōes urbanos, o que, sem dúvida, onerava o custo final do projeto.

Obviamente, os consumidores atendidos por esta modalidade, eram os de mais alto nivel de renda, os quais, podemos dizer, foram quase totalmente ligados.

Restaram, então, os moradores e produtores de média e baixa renda, que não tinham condições de arcar com o ônus da extensão da rede, mas que procuravam a concessionária a fim de obter a eletrificação, fundamental para, não só atender ao célebre objetivo de "fixar o homem ao campo", mas, também, para -melhorar a eficiência da produção, com a conseqüente redução do custo final dos produtos, benefícios estes a serem transferidos à sociedade, como um todo.

A partir de 1981, praticamente, com as linhas de crédito de "dinheiro a baixo custo" fechadas, partiu a LIGHT paraum programa, que foi buscar na experiência adquirida no campo de eletrificação de interesse social - procurando utilizar a forma associativa e participativa - , para compatibilizar a necessidade da eletrificação das pequenas e médias proprieda. des, com legislação do setor e as fontes de recursos disponíveis.

Assim, é que foi iniciado um progra. ma de projetos, por área de penetração, baseado na formulação de pedidos, pelos interessados, nas extensões de redes que, em vista dos investimentos necessários, não puderam arcar com os custos, individualmente.

Procurou-se, então, levantar todas as propriedades, que poderiam ser beneficiadas com a extensão da rede e, através de reunião com os interessados, eram dadas as informações sobre a participação no projeto e o rateio da contribuição não restiturvel. Fizemos, também, as intermediações entre os proprietários e as fontes de financiamento para produção rural, tentando, desta forma, viabilizar a participação de todos. Além disso, o próprio sentido comunitário era desenvolvido e, em mui. tos casos, alguns proprietários arcavam com o ônus de outros e, futuramente, eram ressarcidos com produção agrícola.

Esta prática, aliada a uma revisão dos padrões de eletrificação que, como dissemos anteriormente, eram excessivamente urbanos, adotando o sistema monofásico, principalmente o MRT, com condutor de aço galvanizado, espaçamento de cerca de $300 \mathrm{~m}$ entre as estruturas, que representavam uma reduçāo de cerca de $60 \%$ nos custos dos projetos, em relação ao padrão original, foi possivel permitir que o projeto tivesse uma maior abrangência, alcançando camadas mais baixas nas pirâmides dos consumidores rurais,

No entanto, com o contrato de financiamento assinado entre a ELETROBRÁS e o BIRD, para os programas de Baixa. Renda, favela e rural, foi possivel elaborar-se uma proposta que, a nosso ver, permitirá, não só a todos os proprietários rurais de nossa área de concessão, como, também, mais que isto, a todos os mora. dores da área de concessão da LIGHT, o acesso ao serviço de energia elétrica, colocando a empresa numa posição ímpar, de ter toda a sua área de concessão. atendida pelas suas redes de distribuição de energia elétrica.

A experiência adquirida no atendimento a este mercado "Marginal", deverá refletir na política de comercialização de energia elétrica da empresa.

A organização, quase anárquica do espaço urbano nas favelas, reflete-se, um pouco, no próprio comportamento interno da comunidade e, se de um lado, existe uma população "reconhecida" pelo atendimento de um serviço pú- blico, existe, também, um fluxo no sen. tido contrário, de estar a empresa de serviço público recebendo toda uma contribuição de uma camada margina. lizada da população, sem o atendimen. to do serviço público, sem a propriedade legal da terra, mas que, ao mesmo tempo, representa uma grande massa da populaçäo brasileira e, até - se tomarmos como referência o consumo de energia elétrica - representa a média da população brasileira.

É este conceito de média que devemos ter em mente na prestação de qual. quer serviço público. A tendência da cultura técnica brasileira, presente nas escolas de engenharia, é o atendimento para padrões estabelecidos em outros paises. Desta forma, para atender a estes padrões de confiabilidade, estética, etc., são necessários investimentos mui to acima da capacidade da população e o resultado é que, sempre, uma parcela desta população fica sem o benefício do serviço público, e outra grande par. cela os tem em padrōes bem abaixo da. queles situados nas áreas urbanas de maior valorização. Existe, assim, todo um sistema que verticaliza os investi. mentos públicos, provocando no mapa de qualquer cidade brasileira manchas diferenciadas de atendimento do serviço público.

A experiência do programa de eletrificação de favelas, baixa renda e rural LIGHT, fez com que, não só os padrões vigentes de atendimento comercial, fossem questionados e aos poucos sofrendo modificações, a exemplo dos padrões técnicos de construção de rede de distribuição, já extrapolando a área favela. da para extender-se a outros logradouros, reduzindo-se os custos de investimentos da empresa na extensão de redes de distr.'suição.

A experiência nas reuniōes, com as associaçōes de moradores de favela, fez com que fossem organizadas reuniōes com associaçōes de moradores de bairro, quando os serviços da empresa eram questionados e novos investimentos exigidos. Na explanação dos programas de interesse social da empresa e das prioridades para os investimentos desta, para o atendimento de áreas carentes não atendidas pelo servico público, prestado por estas companhias, travam-se, também, um fluxo de informações sobre a realidade social de outros bairros; desta forma, poderão ser evitados investimentos dentro da filosofia clássica de atendimento. 
A função deste fluxo de informações, que se estabeleceu entre os favelados, população das periferias urbanas e rurais e os técnicos da empresa, serviu, como já dissemos anteriormente, para que estes, também, tomassem conhecimento desta realidade e os padrōes de atendimento e de construção e, o próprio planejamento da empresa, começassem a ser repensados, levando-se em consideração esta realidade, que se passou a conhecer mais de perto.

\section{Setor de energia elétrica: alternativas ao modelo de atuação atual}

\section{MARIO PENNA BHERING}

Presidente da ELETROBRÁS,secretário-execu. tivo do Conselho Estadual de Energia de Minas Gerais e membro do Conselho de Administracăo da ITAIPU Binacional. Engen heiro civil pela Universidade Federal do Rio de Janeiro, com curso de especializaçāo em equipamentos hidráulicos e elétricos nos Estados Unidos, participou da organização da Centrais Elétricas de Minas Gerais, tendo sido seu diretor, vicepresidente e presidente.

\section{Carsctoristicas do modelo}

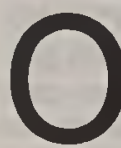
atual modelo da setor de energia elétrica foi concebido em uma fase marcada pela precariedade dos servicos, com problemas freqüentes no atendimento do mercado consumidor.

A existência de potencial hídrico abundante, com aproveitamentos baratos, porém intensivos em capital e de longa maturação e a ausência de um mercado financeiro privado capaz de atender as necessidades de recursos, levaram o Governo a assumir o encargo de promover a expansão do sistema e adequá-lo às exigências do processo de crescimento econômico.

Do ponto de vista organizacional, o Governo Federal responsabilizou-se pelo planejamento setorial e pela execução das obras de geração e transmissão, através do Grupo ELETROBRAS, enquanto que os governos estaduais constituíram em. presas dedicadas principalmente à distribuição da energia elétrica. Essas empresas, através de fusōes e absorção de pequenas concessionárias locais, são hoje, de um modo geral, responsáveis pela distribuição no âmbito dos respectivos Estados.

No que concerne ao processo decisório e a forma de atuação, alguns fatores foram de importância capital para a definição das características atuais do modelo setorial. Em primeiro lugar, o modelo consolidou-se ao longo de um perlodo caracterizado por altas taxas de crescimento do mercado, inicialmente devido a demanda reprimida $e$, na etapa posterior, em decorrência da expansão acelerada da economia.

A resposta da sociedade às pressões do mercado consistiu na atribuição de uma prioridade elevada à expansão da oferta de eletricidade, traduzida pela definição de um intenso programa de investimentos, centrado em grandes obras, que, não obstante a larga soma de recursos demandada e os longos prazos de retorno do capital, correspondiam à opcão economicamente mais vantajosa.

O financiamento do programa, essencialmente com recursos próprios, foi assegurado pelo Governo, tanto indiretamente, pela concessão de tarifas compat'veis com o nivel de recursos exigidos, como diretamente, pela subscrição de capital e reinversão dos dividendos.

A alta prioridade atribulda ao setor e a relativa facilidade de captaç̃o de recursos condicionaram o seu planejamento, direcionando-o para o atendimento integral da demanda prevista, sem atenção às possibilidades de influir sobre o mercado e adequá-lo às conveniências do Pals.

A preocupação $c 0$ a satisfação plena do mercado conduziu, ainda, ao estabelecimento de niveis elevados de garantia de suprimento, com o dimensionamento do sistema, de modo a assegurar um risco pequeno de déficit de energia elétrica, mesmo nas condições mais adversas.

Dentro dessas premissas, o planejamento reduz-se a um processo unidirecional, em que, uma vez prevista a expansão do mercado, é determinado o programa de obras que atenda à expansão prevista dā forma mais económica. Subjacente está o pressuposto de que os recursos financeiros serëo disponfveis, resumindo-se o planejamento financeiro ao equacionamento da captação desses recursos.

A preponderância do aspecto econômico sobre o financeiro emprestou uma ênfase acentuada aos grandes projetos, com maiores economias de escala. A opçäo por empreendimentos de maior porte tornou-se possivel pela concentração do processo decisório, ao mesmo tempo que a reforcava, e provocou um processo paralelo de concentração dos recursos, com a criação de mecanismos de transferência de recursos entre as empresas e destas para a ELETROBRẢS.

Outra conseqüência dos fatores con- 